\title{
SOIL FERTILITY PROBLEMS OF TARANAKI
}

By A. C. BURGESS, Instructor in Agriculture, Department of Agriculture, New Plymouth, and E. B. DAVIES, Senior Chemist, Rukuhia Soil Research $\mathrm{S} t$ a t i o n, Hamilton.,

\section{FIELD OBSERVATIONS (A. C. Burgess)}

Soils

A description of the soils of the district was given in the first paper of the Conference and here it is necessary only to repeat that the soils of Taranaki can be divided into the following groups:-

(a) The volcanic soils of the easy, rolling and hilly country in the western part of the district.

(b) The steep hilly soils of the eastern part of the district, coniposed of papa and sandstone.

(c) The swampy soils in the Rahotu-Oaonui, Pihama-Kapuni, and Tariki-Inglewood areas. Ratapiko.

(d) The peaty loams at Ngarere, Stratford, and

(e) The recent soils of the river flats.

The volcanic soils known as the yellow-brown loams are light in texture, free draining, and easily worked. They dry out fairly quickly, but with a good rainfall droughts are not often serious.

The swampy areas have an iron pan developed at 2 to $3 \mathrm{ft}$. in many parts and are. difficult to drain, but some high producing farms have been developed on them. Drainage is of course the main problem on the peaty soils, but it has been done well on many farms, and quite high production is being attained.

The soils of the river valleys are in general very rich, especially, the silts which are formed as wash from the papa hills, but here again drainage limits their production by making growth later in the spring and pugging in wet weather allows weeds such as penny-royal, redshank, and buttercup to get'a foothold, further reducing production of grass.

\section{Soil fertility}

The first impressions of the early settlers in Taranaki were that the soil was very rich, but they soon 
found to their sorrow that this was not so. Through falling fertility pastures were difficult to maintain in condition, stock did not thrive easily, the death rate was high and production low.

Some farmers gave up their holdings after a few years because they saw no solution to the problem ; others commenced to use artificial phosphatic fertilisers as early as 1900. Topdressing was not practised to any extent until about 1916, however, and this marked the beginning of a new era of farming.

Trials have been conducted throughout the district 'for.20 to 25 years in an endeavour to find what soil deficiencies occurred and to compare the value of the different fertilisers on the market.

\section{Lime}

The first important fact established by trials is that on volcanic soils little response can be expected, from lime even at rates up to 2 tons per acre. This is supported by chemical analysis which shows that the $\mathrm{pH}$ value (i.e. the acidity) of farm soils in the volcanic group varies from 5.7 to 6.5 , which, although it is acid, is in the best range for vigorous pasture growth. Some of the volcanic 'soils are lower than the optimum in available calcium and would benefit from lime to build this up, but the calcium does build up with the regular heavy phosphate applications which are necessary for. high production.

The swampy areas with the iron pan layer do not appear to be any more lime deficient than the volcanic soils, but good responses have been observed on 'the peat soils and on the papa sandstone hills. On the hills, however, topdressing with lime largely becomes a matter of economics. No responses have been observed on the river flat soils.

\section{Phosphate}

Ample phosphate has always been the key to suecessful pasture growth in Taranaki and good responses have been recorded in all trials conducted. Differences due to soil type have been small, although South Taranaki soils have generally shown smaller responses than those further north. Responses on peat and hill country and river flats have been equally as good as those on volcanic soils.

Early chemical analysis of Taranaki soils indicated that phosphate was very high and the soils were considered by some to be of high natural fertility. Samples taken about 3 years ago from a part of the 'dis-. 
trict which had had little topdressing and which had not been intensively farmed showed, however, that there was little or no available phosphate present. Topdressing at normal rates is slow to improve the supply and here lies the key to our main problem with phosphate in volcanic soils, that of fixation. This will be dealt with in more detail by Dr. Davies.

The type of phosphate most suited to Taranaki soils has always been a much debated 'question. Generally the trials have revealed very small differences in response to the more common phosphates in use, but it could be said that basic slag and serpentine' super have been slightly better than super, with Gafsa or North African phosphate and ground Nauru rock phosphate poorer in that order. Heskett slag has never shown to advantage in any trial.

On the silt, sand, and papa sandstone soils super has responded well and is probably the most efficient form of phosphate. The recent soils exhibit lower fixing properties than the volcanic soils and in their case this may explain the superiority of superphosphate.

\section{Potash}

Potash has played an increasingly important part in high pasture production on the volcanic soils of Taranaki over the past 25 years and good responses have now been recorded on them in all parts of the Province. The soils in South Taranaki appear better supplied than those in Central and North Taranaki..

Although there is no doubt that on these soils potash is now as important as phosphate, the fact that both are needed should not be lost sight of. A deficiency of one may mask a response to the other.

No responses have yet been observed on river silts or papa sandstone soils, but on the swampy soils good results have been obtained, and on peat one trial has shown outstanding responses at rates up to $5 \mathrm{cwt}$. per acre.

\section{Nitrogen}

Clover is the key to the nitrogen supply of pastures and once pastures are well established there appears to be little need to supply artificial nitrogen even to grow grass in the winter and early spring. Autumn sown pastures which generally produce a flush of xyegrass in the first few months, however, often appear to suffer from nitrogen starvation. in the spring. 
Clover disappears and grasses are left brown and stunted.

The condition is sometimes only temporary, but on numerous occasions it has been observed to persist until the following spring.

One particularly bad paddock this year was treated with lcwt. of sulphate of ammonia and 3cwt. of lime in the early spring and within one month had, commenced to grow a dense mat of clover. Strips missed with the drill could be plainly seen, still brown and stunted. The paddock had grown practically nothing for 9 months. Apparently the nitrogen had been depleted by cropping, and the ryegrass had further used most of the remainder, so that there was insufficient even for the clovers to get a start and be able to produce their own nitrogen. Experiments are being carried out with nitrogen applied with the seed on poor soils where it is possible that low nitrogen may retard germination and prevent good establishment.

\section{Rates and times and frequency of application}

While average dressings of 2 to $3 \mathrm{cwt}$. per acre of phosphate seem to have little effect in improving. poor pastures on the volcanic soils, outstanding improvement has been brought about when dressings of $4 \mathrm{cwt}$. up to even 10cwt. per acre of phosphate have been used. It would appear that such heavy dressings are necessary to give a good build up quickly. Results of a large number of quick test analyses of soils also have indicated that the phosphate level is not built up very high until regular fairly heavy applications are made. A dressing of at least lcwt. per acre of muriate of potash is shown by trials to be necessary to bring the potash level up in a reasonable time and results of analyses confirm this. Once the build up has been achieved normal dressings of 3 to $4 \mathrm{cwt}$. of phosphate and $\frac{3}{4}$ to lcwt. of potash should be sufficient.

Time of application is important. It is generally recognised that fertilisers applied in the growing season, i.e., autumn or spring will give better results than that applied in midsummer or midwinter. Winter is probably the worst time and farmers would be well advised to store fertiliser for a month or two rather than apply it then.

The best results are achieved by those farmers who topdress in both autumn and spring.

A general recommendation for volcanic soils and the swampy soils would be: On new grass or poor 
pasture which will not be ploughed: 8 to $10 \mathrm{cwt}$. of phosphate and lcwt. of potash in two dressings, spring and autumn, followed by annual applications of 5 to $6 \mathrm{cwt}$. of phosphate and lcwt. of potash also divided into spring and autumn dressings.

For hill country or sandy soils 2 to 3cwt. of phosphate in autumn should be sufficient. : Lime should be considered on the hills as should an occasional dressing of potash on easy country covered with volcanic soil.

No recommendations will be made here regarding peats as this is the subject of a later paper.

\section{Cropping}

As has been indicated earlier, cropping may seriously reduce the supply of available nitrogen in the soil and too much cropping, especially with such crops as oats left for hay, or maize, should be avoided. Choumoellier is a crop which is unable to take up phosphate readily, which may account for poor results 'when it is sown as a second crop. It is important, in any case, to provide ample fertiliser for crops including nitrogen if necessary, and also to remember that grass will out-yield any other crop known, so that when old grass is ploughed, the sooner it is sown back to new grass the better.

\section{LABORATORY OBSERVATIONS (E. B. Davies)}

The above discussion of Taranaki soils, based largely on field experience, will be supplemented by a few observations based rather on examination of soil samples in the laboratory.- It is proposed to confine remarks, for the most part, to the volcanic soils. (yellow-brown loams), the most important soils in the area.

\section{Physical nature and organic matter content}

The light, friable nature of the yellow-brown loams may be attributed to their very high content of organic matter. Loss on ignition figures of the moisture free soils range up to almost 30 per cent. while organic carbon may be as high as 12 per cent. The carbon-nitrogen ratio is fairly low, denoting that the organic matter is mature. In texture the soils range from silt loams to gravelly sands. The clay contents of the former may range as high as 20 per cent. Physically the soils are an ideal medium for plant growth.

\section{Supply of plant nutrients}

The soils are derived from andesitic ash and are 
well provided initially with the bases calcium and magnesium, but not so with potassium. As the soils have developed, bases have been leached out to extents depending largely on the rainfall. One would expect the exchangeable $\mathrm{Ca}, \mathrm{Mg}$ and $\mathrm{K}$ figures to diminish progressively as one passes from regions of 40in. to 150in. rainfall. Superimposed, however, on the climatic effect is that of, farming operations. Soils will vary from field to field- according to management and fertiliser and lime applications and the pattern found in virgin soils may be masked. The power of soils to absorb bases is a characteristic feature which varies from soil type to soil type. In the case of the yellow brown loams this power is remarkably high-a fact associated with the unusual level of organic matter. The absorptive capacity is rarely much more than 50 per cent. satisfied and frequently much less. The soils are less acid than would be expected under this circumstance. In technical language low percentage saturations are accompanied by high $\mathrm{pH}$ values.

The general run of Taranaki soils examined are low in available phosphate (Truog test) in contrast to the total phosphate figures, which, in the small number of soils examined, are exceptionally high.

Of the trace elements boron is needed as evidenced by the occurrence of brown heart in swedes. This applies more particularly to the higher rainfall areas. A probable copper deficiency, as far as animal heaith is concerned, occurs in peats at Eltham and Ratapiko. Apart from these, trace element deficiencies have not been noted. Molybdenum determinations have been carried out on a number of Taranaki soils and the level found satisfactory.

\section{F ate of added fertilisers}

The removals of phosphorus and potassium in produce are much smaller than the additions made by way of topdressing. Amounts taken up in pasture growth are to a large extent returned to the soil through the grazing animal. The elements must either accumulate in the soil in an unavailable form, or be lost in drainage, for continuous topdressing seems necessary.

At the conclusion of his "Introduction to Taranaki," Mr Burgess showed slides of a Taranaki farm and homestead. This same farm has afforded an opportunity of. tracing the fate of fertiliser additions, for accurate records have been kept from as far back 
as 1896 of fertiliser additions and butterfat production. The soil, Stratford sandy loam, can be considered as exemplifying the Taranaki yellow-brown loams. In 1929 a fence line was placed across a field last ploughed in 1924. Soil from under this fence line has been taken as representative of the soil as in 1929, in contrast to a field sample modified by fertiliser additions and removals in produce since that time. Silage has been cut each year, but fed off in the same paddock.

The phosphate balance will first be considered:

\section{Total Phosphate}

(Figures are expressed as milligrams per cent. $\mathrm{P}_{2} \mathrm{O}_{5}$ )

$$
\text { 0-3in. } \quad 3 \text {-6in. }
$$

$\begin{array}{llr}\text { Field re } & 592 & 455 \\ \text { Fence line : } & 439 & 424 \\ \text { Difference } & 143 & 31\end{array}$

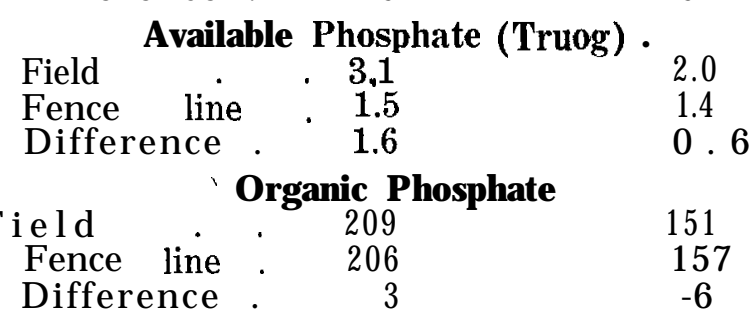

The difference between the field and fence line samples shows the total phosphate to have been increased greatly over the period, particularly at the O-3in. depth. Organic phosphate has remained practically constant. It follows that the stored phosphate must, be fixed in an inorganic form-probably as -basic iron and aluminium phosphates. This is in striking contrast to Dr. Jackman's findings (see later paper) on Taupo pumice soils, namely that the accumulation of phosphate in soils under permanent pasture is predominantly in organic form.

In the period 1929-51 phosphate equivalent to 3.15 tons of super was applied as topdressing. Assuming an acre 3in of moisture free soil to weigh 550,000 pounds, the gain of phosphate in the field sample would represent 2.13 tons of super. Removal as milk and cullings over the 22 years could reasonably account for 0.4 tons of super, leaving 0.62 tons, 20 per cent. of the application untraced. It is obvious, that the main part of the added phosphate remains in the soil, yet the test for available phosphate is but little affected 
and a phosphate response is evident in a topdressing trial in the field in question. The phosphate dressings had been reduced to lcwt. per acre for the past 3 years.

\section{Potash}

Potash salts have been applied to the field from 1933 onwards, in all the equivalent of $8.75 \mathrm{cwt}$. of 60 per cent. muriate of potash per acre. Despite this, exchangeable potash in the field is lower by 0.08 and 0.07 milli-equivalents per cent. in the O-3in. and 3-6in. samples respectively, an, amount representing roughly $0.55 \mathrm{cwt}$. of muriate of potash. The equivalent of $9.3 \mathrm{cwt}$. of the muriate has apparently been lost, and of this but 2.3cwt. could be counted against produce.

The exchangeable potash in the soil can be represented as in equilibrium both with non exchangeable potash and with potash in solution.

Non exchangeable potash $\underset{\text { potash }}{\operatorname{exchangeable}} \rightleftharpoons \underset{\text { solution. }}{\text { potash in }}$.

The added potash salts would first be taken up in the soil as exchangeable potash. There then exist the alternative possibilities of conversion to a non exchangeable form, and this is considered unlikely, or on the other hand, passage to the soil solution and loss in the drainage. From the figures quoted it seems likely that potash equivalent to $361 \mathrm{bs}$. of muriate of potash has been lost each year in this latter manner.

Balance sheets worked out in a like manner for calcium and magnesium show annual losses of calcium equivalent to $2.69 \mathrm{cwt}$. of carbonate of lime and of magnesium equivalent to $0.26 \mathrm{cwt}$., again expressed as the carbonate. The latter figure is qualitative only owing to some doubt as to amounts of serpentine super used, and the rate of break 'down of serpentine fragments in the soil. Two cwt. of serpentine super a year would more than make good the loss.

Dixon and Taylor (1) have pointed out similar losses of potash and magnesia in the; Waikato on long topdressed soils and show that the 50 per cent. of gypsum present in superphosphate can be held responsible for accelerated removal of these bases by leaching. It is probable that the same process is occurring in Taranaki. The loss of potash is evidenced in continued need for topdressing. Magnesium levels are as yet still adequate but continued depletion will lead to deficiency. 


\section{Phosphate availability}

The phosphate in the'field described to 6in. depth would be equivalent to about 13 tons of super per acre, yet the pasture still responds to topdressing. Experiments have been carried out with a sample of New Plymouth silt loam (reputedly unmanured) from the Katere area containing even more total phosphate. Figures for total and exchangeable phosphate and various measures of availability'are given in the table.

\section{Phosphate Content of New Plymouth Silt Loam}

Total phosphate (Sherman's method) $\mathrm{Mg}$ per cent. $\mathrm{P}_{2} \mathrm{O}_{5}$

"Total phosphate" (soluble in boiling $\mathrm{HCl}$ ) 481

Exchangeable phosphate (extracted with neutral $\mathrm{N} \mathrm{NH}_{4} \mathrm{~F}$ ). . . 106

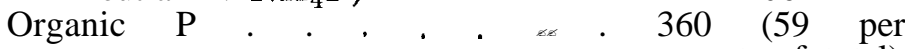

Available phosphate :

1 per cent citric acid method . . . 29

Egner's lactate extractant . . . 0.7

Truog's ex tractant $\quad$. $\quad 1.5$

Mitscherlich pot culture' method . . 3.3

The figures for total and exchangeable phosphate are' extremely high compared with most New Zealand soils. The citric acid soluble phosphate suggests an adequate supply available for plant nutrition, the Egner and Truog tests an extreme deficiency. The Mitscherlich test based on plant growth supports these latter figures.

A pot experiment using subterranean clover'as an indicator plant was run on a further soil sample from the same area. The effect of heavy liming with and without added phosphate was investigated.

Yields of subterranean clover on New Plymouth silt loam

Yield in grams dry matter No per. pot No. Superphosphate
Phosphate

Lime to 40 per cent. saturation 1.72 9.28

Lime to 10,0 per cent. saturation $1.02 \quad 11.84$

Dolomite to $\mathbf{1 0 0}$ per cent. satu-
ration ...
... $\quad 0.74$
11.22

Treatments were in quintuplicate.

Without added phosphate there was very little growth and even less' with heavy liming. The' addition of superphosphate resulted in good growth fur- 
ther increased by liming to saturation. It would seem that the store of phosphate in the soil was almost wholly unavailable, at any rate to oats (in Mitscherlich test) and subterranean clover. Extremely high contents of citric acid soluble phosphate in Taranaki soils have previously been indicated (2) but both field and laboratory trials suggest that such, is no true indication of availability.

\section{Conclusion}

Taranaki's main fertility problems' are the apparently insatiable appetite of the yellow brown loams for phosphate, which phosphate is accumulated in a form difficult for plants to use, and the losses of potash-an expensive fertiliser to pour down the drain. The need is for a phosphate fertiliser less prone to fixation than super and yet available for plant nutrition, and preferably one that does not contain 50 per cent. calcium sulphate. The Department of Agriculture, has in progress field trials with "Metaphps," tricalcium phosphate (a fused defluorinated rock phosphate) and double super. Early indications from pot experiments at the laboratory suggest that finely ground rock phosphate, more particularly with a heavy initial dressing, may be effective. The threatened sulphur shortage has concentrated attention on phosphatic manures alternative to super and the stimulus may hasten the ultimate solution of the problem posed.

\section{References}

(1) Dixon, J. K. and Taylor N. H. (1942) N.Z. J. Sci. Tech. 24, 146A-151A.

(2) Rigg, T. (1932) Annual Report 7, N.Z. D.S.I.R. $\mathrm{p}$

Acknowledgment is made to members of the staff of the Rukuhia Soil Research Station who carried out the analytical work involved in this paper.

\section{DISCUSSION ,}

Q. What proportion of organic phosphate in the experiment described was unavailable?

A. Did not know, but pointed out that in the pot experiments described there was little growth in the absence of applied phosphate, despite the high content of organic phosphate in the soil, and negligible amount could have been utilised.

$$
: 55
$$


Q. 1. What was the fineness of grinding of the rock phosphate in the experiments mentioned in the concluding remarks?

2. Would the speaker agree with Sears's work at Grasslands showing the importance of the sulphur content in superphosphate?

3. Had the extent of fixation of rock phosphate been determined?

A. 1. Four grades of fineness were used in the experiment. 72 to 85 mesh, 150 to 170 mesh,' 40 to 50 microns (just finer than 300 mesh), 5 microns approximately.

Ordinary pulverised rock phosphate would contain quite a proportion of the 40 to 50 micron material.

2 . The gypsum would supply calcium but have no effect on $\mathrm{pH}_{3}$ Sulphur is an essential plant nutrient, but the speaker had not heard of deficiencies in New Zealand! apart from Dr. Doak's work with lucerne. If fertilisers containing no sulphate were used, sulphur deficiencies might develop in time.

3. Fixation of phosphate from rock phosphate had not been determined.

Dr. Grange expressed the opinion that in Taranaki volcanic soils heavy initial liming, sufficient to saturate the soil, should improve the utilisation of applied phosphate. Followmg this, small applications of about 2cwt. of lime should suffice and thus conserve phosphate. 